\title{
Selection criteria in postgraduate osteopathic medical education
}

\author{
BRUCE P. BATES, DO \\ CHARLOTTE K. BATES, MA \\ KAREN TOLSTRUP
}

\begin{abstract}
Program directors of rotating internships and residency programs in general practice, internal medicine, obstetrics-gynecology, general surgery, orthopedic surgery, and pediatrics were surveyed concerning the relative

importance of 10 academic and 10 nonacademic variables related to trainee selection. Study findings demonstrated that the interview was the most highly valued aspect of the selection process, and that, overall, interpersonal nonacademic factors were rated more important than academic factors. Implications for program selectors, students, and osteopathic medical colleges are discussed.
\end{abstract}

During the past decade there has been a significant increase in the number of colleges of osteopathic medicine and a concurrent increase in the number of graduates. In turn, the demand has grown for postgraduate programs to keep pace numerically without sacrificing quality. Students also are feeling more pressure as it becomes more difficult to enter programs of their choice.

Many allopathic specialty groups have begun to assess the selection criteria for their postgraduate programs. In the osteopathic community as well, there is a need to identify the criteria used to select postgraduate trainees. A computerized literature search was performed by the University of New England library staff to identify articles involving selection factors for internship and residency programs. More than 26,000 articles were cited, but not one directly involved students of osteopathic medicine or osteopathic programs.

The present study was undertaken to identify criteria used in the selection of postgraduate trainees in the osteopathic profession. Also, the relative importance of each criterion is rated in both the osteopathic and allopathic professions.

\section{Report of study \\ Background studies}

In the late 1970 s, Wagoner and Gray ${ }^{1}$ asked a national sample of $25 \%$ of allopathic postgraduate program directors in internal medicine, surgery, pediatrics, and family medicine to judge the importance of 31 variables in selecting residents. The rank ordering showed interpersonal skills to be the most important criteria.

Leonard and Harris ${ }^{2}$ in 1980 surveyed 24 fulltime faculty members at a University of Minnesota teaching hospital to determine the importance of various selection criteria for a primary care internal medicine residency program. Respondents' highest ratings went to 'good' grades in clinical work, favorable dean's letter and other letters of recommendation, top internal medicine subscores and total scores on part II of the National Board of Medical Examiners, and personal knowledge of those recommending the student. Responses to open-ended questions revealed, however, that selectors placed the greatest weight on personal and interpersonal qualities, which they considered to be more important than academic success.

In 1983, Featherstone and Ramsey ${ }^{3}$ questioned a sample of 17 faculty members on resident selection committees at one institution to determine whether there was a difference in criteria between primary care and specialty committees. Both committees selected performance in medicine clerkships and a positive recommendation from the department chairman as most important, while per- 


\begin{tabular}{|c|c|c|c|c|c|}
\hline Rank & Criterion & Mean & SD & $\Sigma$ & SE \\
\hline 1 & Interview & 4.43 & .74 & .59 & .06 \\
\hline 2 & Ability to work with others & 4.39 & .65 & .42 & .05 \\
\hline 3 & Maturity & 4.36 & .67 & .45 & .05 \\
\hline 4 & Performance in your program & 4.33 & .79 & .63 & .06 \\
\hline 5 & Work habits & 4.31 & .70 & .48 & .06 \\
\hline 6 & Clinical judgment & 4.28 & .66 & .43 & .05 \\
\hline 7 & Problem solving ability & 4.18 & .69 & .48 & .06 \\
\hline 8 & Overall clerkship performance & 4.13 & .82 & .67 & .06 \\
\hline 9 & Clerkship medical knowledge & 4.10 & .61 & .38 & .05 \\
\hline 10 & Clerkship technical skills & 3.49 & .81 & .67 & .06 \\
\hline 11 & Clerkship performance in other specialties & 3.33 & .98 & .95 & .08 \\
\hline 12 & Grade point average & 3.22 & .88 & .78 & .07 \\
\hline 13 & Class rank & 3.15 & .89 & .79 & .07 \\
\hline 14 & Other letters of recommendation & 3.07 & 1.01 & 1.03 & .08 \\
\hline 15 & Part II Osteopathic National Board score & 2.70 & .89 & .80 & .07 \\
\hline 16 & Geographic preference & 2.66 & 1.24 & 1.55 & .10 \\
\hline 17 & Part I National Osteopathic Board score & 2.65 & .90 & .81 & .07 \\
\hline 18 & Preclinical grades & 2.63 & .91 & .96 & .08 \\
\hline 19 & Dean's letter & 2.54 & 1.16 & 1.35 & .09 \\
\hline 20 & Medical school attended & 2.09 & 1.08 & 1.17 & .09 \\
\hline
\end{tabular}

sonal characteristics were a major factor in weeding out undesirable candidates. Primary care selectors emphasized the potential trainee's personal goals, skills, interests, and stated career plans more than their nonprimary care associates, who valued recommendations from colleagues and the perceived quality of the student's medical school more highly.

Clarke and Wigton ${ }^{4}$ in 1984 developed an objective rating system for use in selecting surgical residents. They chose five attributes - knowledge, judgment, technical skills, work habits, and interpersonal skills - as being most important. In the study, 12 faculty members evaluated 25 applicants. It was found that a third of the assessment weight was given to knowledge, and half to knowledge plus judgment. Evaluation forms, deans' letters, and standard letters of recommendation were considered to be of equal value as sources of information.

Seven years after their original study, Wagoner and coworkers ${ }^{5}$ surveyed a random sample of 405 postgraduate allopathic medical education program directors and department chairmen concerning their resident selection process. Forty-eight variables were rated on a scale from 1 (unimportant) to 5 (critical). Analysis of the data from the 237 respondents supported the earlier study; it again showed that the interview was the most important criterion. However, increased emphasis was placed on students' academic records in the latter study. Of the academic criteria ranked, the most important were grades in clerkships in the program director's specialty, grades in elective studies in the program director's specialty, and grades in other clerkships, in that order. Applicant characteristics of highest importance were compatibility with the program, ability to grow in knowledge, maturity, and commitment to hard work.

Finally, Sade and associates, ${ }^{6}$ from a different point of view, attempted to develop a valid description of the 'superior physician' as a first step in devising a tool to select medical students. Of the 87 characteristics ranked by medical school faculty members, the top five were good clinical judgment, habitual performance of 'as thorough an examination of each patient as required for accurate diagnosis and proper treatment,' up-to-date knowledge, emotional stability, and good doctor-patient relationship. These authors studied the 'teachability' of their 87 characteristics and concluded that those among the most highly valued were also the most difficult to teach in the medical school setting.

\section{Methods}

Based on a sampling of the 1985-1986 American Osteopathic Association Directory ${ }^{7}$ survey forms were mailed to 344 program directors of osteopathic rotating internships and residency programs in general practice, internal medicine, obstetrics-gynecology, general surgery, orthopedic surgery, and pediatrics. Questionnaires were sent to small community hospitals and college-related institutions in proportion to their representation within the postgraduate programs.

The respondents were asked to rate 20 variables (10 academic, 10 nonacademic) related to trainee selection. These criteria were elicited from the data that directors of medical education of hospitals with postgraduate programs requested most commonly from osteopathic college deans. The rating scale 
ranged from 1 (unimportant) to 5 (very important).

Results

Overall results. The study respondents totaled 157 program directors, for a survey return rate of $45.6 \%$. Table 1 lists the overall ratings of the criteria in rank order, as based on the means of the total responses. Nonacademic criteria predominated in the top ten categories. As in the Wagoner studies,,$^{1,5}$ the interview was the most highly valued aspect in the selection process. The candidate's demonstrated ability to work with others and maturity were the two next in importance. The highest rated academic variable was performance in the clerkship in the selecting director's program.

Basic science grades on part I of the National Board of Examiners for Osteopathic Physicians and Surgeons and preclinical grades were ranked as being of lesser value than clerkship performances, and letters of recommendation from the college dean were still lower in importance. While a prestigious medical school traditionally has been considered a valuable "ticket" to desirable programs, the respondents indicated that this criterion barely deserves recognition.

It appears that what distinguishes the outstanding from the average candidate is the possession of nonacademic qualities and attitudes esteemed by the osteopathic community.

Academic variables. Table 2 rates the academic criteria for selection of osteopathic postgraduate trainees for rotating internship and specialty residencies. Accomplishment in clerkships was weighted most highly in all programs. Performance in the clerkship program of the selector was rated most important in the specialties, but overall clerkship performance was most important in the selection of trainees for rotating internships. This finding is consistent with the more general nature of the rotating internships in the osteopathic profession. It should be noted that the academic criteria judged most important were in the areas of performance and use of knowledge, while National Osteopathic Board parts I and II scores and preclinical grades were of lesser importance. Ironically, these three items dominate the students' thinking. Especially in the earlier phases of education, this leads to a competitiveness that is contrary to the collegiality, teamwork, and mutual support that are paramount in a clinical setting.

Nonacademic variables. Table 3 shows the rankings of nonacademic criteria in choosing osteopathic postgraduate trainees. For rotating internships, general practice residencies, and residencies

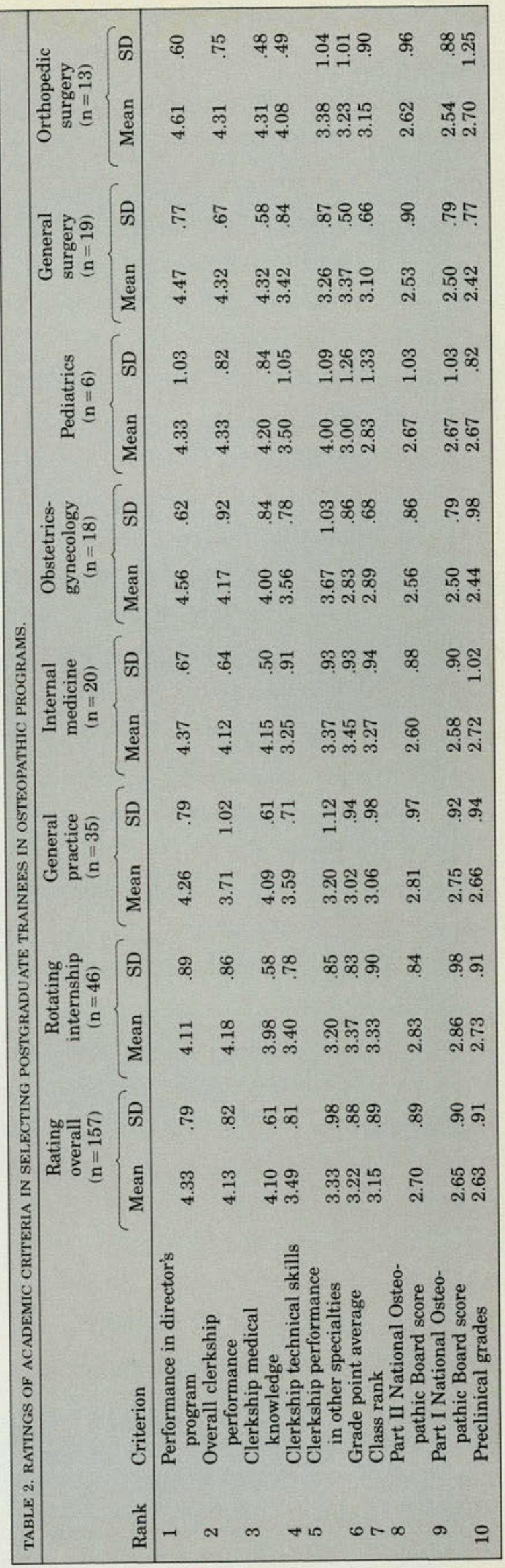




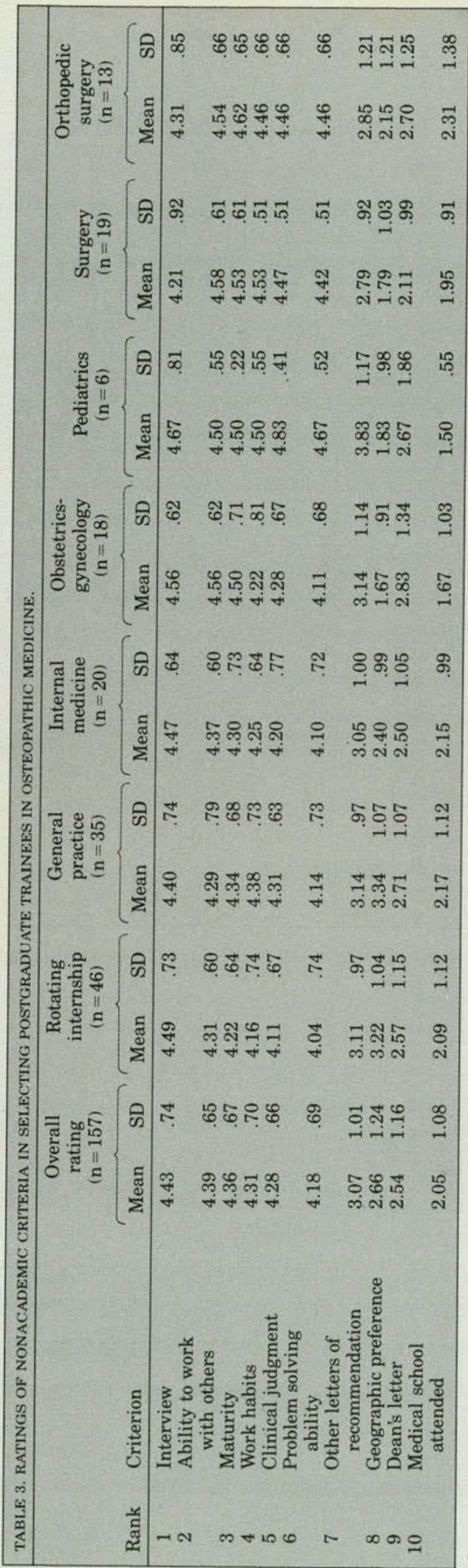

in internal medicine, the interview was considered the most important variable, with ability to work with others and maturity following. In obstetricsgynecology, the interview was tied with the ability to work with others. In pediatrics, clinical judgement was first, with the interview tied with problem-solving. General surgery and orthopedic surgery programs, while ranking the interview as very important, judged maturity, ability to work with others, work habits, clinical judgment, and problem solving higher.

Letters of recommendation from sources other than the medical college dean were of some importance, but letters from the dean were not valued highly. Perhaps the deans' letters are thought to be influenced by college politics. Or, it may be that other letters of recommendation are considered to be more reflective of program needs and similarities, as well as reflections of greater personal knowledge and involvement with a particular candidate. Of least importance was the medical school attended by the candidate.

\section{Discussion}

The findings in our study demonstrated that there is an emphasis on nonacademic interpersonal qualities in osteopathic programs. This is roughly equivalent to the nonacademic emphasis in allopathic primary care. Differences between our study and the background studies seem to emerge when primary care is compared with specialist care. However, Wagoner ${ }^{5}$ found a marked increase in the importance of academic criteria over a seven-year-period. On the other hand, our study revealed that while clerkship performance presently was considered important, other academic criteria were not that highly valued.

Nonacademic qualities are more highly valued among osteopathic programs in general than they are among the allopathic specialties. Also, interpersonal qualities are more important among osteopathic specialty programs than they appear to be among allopathic specialty programs. The data are consistent with the philosophy of osteopathic medicine and its emphasis on primary care.

When the importance of various academic variables is compared between the osteopathic and allopathic professions, the highest value in both is given to clerkship performance in the selector's area; this is followed by overall or other clerkship performance. These findings are not surprising, because program directors undoubtedly are more knowledgeable and comfortable with aspects of their own specialties.

The selection criteria that program directors ranked as important may not be considered equally 
important by students, who tend to focus on shortterm priorities, such as gaining admission to medical school or passing the next required course. In the preclinical years, students emphasize the acquisition of knowledge to get good grades and pass National Board examinations. Students tend to spend their elective clerkship time in activities that are directed toward gaining a postgraduate position. As the General Professional Education $\mathrm{Panel}^{8}$ points out, such a practice may compromise a solid general education. Academic success does not necessarily result in good clinical judgment, the fostering of independent learning skills, or problem solving abilities. Given the changes occurring in the health care system today, human relationship skills are as important to health care as the knowledge of acute illness.

\section{Conclusions}

Because of the emphasis on nonacademic factors in choosing trainees for rotating internships and residencies within the osteopathic profession, there are implications for three areas: (1) program directors' measurement of these criteria; (2) students' perception of these criteria; and (3) the colleges' role in developing the qualities considered to be important.

Medical directors know what characteristics are valued in their programs, but there is no method yet available for systematic measurement of these qualities. Program directors should continue to gather the readily available academic information, but even small community hospitals must develop a way to measure the criteria that are important to their particular needs. The larger task is to find a way to measure these criteria from candidate to candidate.

In applying for internships and residencies, students should become more aware of how to present their nonacademic qualities to program directors. In the pressure of competition for grades, they tend to devalue the psychosocial aspects of medicine. Despite the pressure of the postgraduate program chase, students should spend as much time devel- oping their "soft" interpersonal skills in the medical humanities as they do in honing their didactic skills.

In addition, colleges of osteopathic medicine should consider whether the nonacademic qualities rated as important in choosing interns and residents can be developed over the course of study and, if so, how best to bring this about. With the rapid advances in medical technology, there has been an increased demand on students to learn vast amounts of information. Consequently, there may have been relative neglect in helping students to acquire the values, attitudes, and interpersonal skills that are found in the superior physician.

If, on the other hand, medical educators believe that these qualities already are inherent by this stage of life and cannot be influenced greatly by the osteopathic educational experience, then those persons responsible for choosing who will be accepted at the colleges of osteopathic medicine should consider these qualities as they select the next year's students.

1. Wagoner NE, Gray GT: Report on a survey of program directors re garding selection factors in graduate medical education. $J$ Med Educ 1979;54:445-452.

2. Leonard A, Harris I: An approach for defining selection criteria of applicants for medical residency training. $J$ Med Educ 1980;55:57-59.

3. Featherstone HJ, Ramsey P: Analysis of selection criteria for medical residents. Am J Med 1983;75:687-690.

4. Clarke JR, Wigton RS: Development of an objective rating system for residency applications. Surgery 1984;96:302-307.

5. Wagoner NE, Suriano JR, Stoner J: Factors used by program directors to select residents. J Med Educ 1986;61:10-21.

6. Sade RM, Stroud MR, Levine JH, et al: Criteria for selection of future physicians. Ann Surg 1985;201:225-230.

7. 1985-1986 Yearbook and Directory of Osteopathic Physicians, ed 77. Chicago, American Osteopathic Association, 1985.

8. Panel on the General Professional Education of the Physician and College Preparation for Medicine: Physicians for the Twenty-first Century. Washington, DC, Association of American Medical Colleges, 1984.

From the Department of Clinical Affairs, University of New England College of Osteopathic Medicine, Biddeford, Me.

Reprint requests to Dr Bates, University of New England College of Osteopathic Medicine, Hills Beach Road, Biddeford, ME 04005 . 